Proc. 13th International School on Theoretical Physics: Symmetry and Structural Properties of Condensed Matter

\title{
Study of Static Young Modulus of Hydroxyapatite
}

\author{
T. WięCEK*, A. WAsileWski And M. KUlig \\ Rzeszów University of Technology, al. Powstanców Warszawy 12, 35-959 Rzeszów, Poland
}

\begin{abstract}
This paper describes laser system to measure the static Young modulus of porous ceramic. Hydroxyapatite was used as porous ceramic. The laser system based on the diffraction of light was designed and built by the authors and the impulse excitation technique was produced by IMCE (Belgium). As different methods are applied for determination of the Young modulus it was necessary to perform a comparison analysis of the results received from both methods.
\end{abstract}

DOI: 10.12693/APhysPolA.135.1283

PACS/topics: 62.20.Dc, 42.62.-b,07.60.--j

\section{Introduction}

In recent decades, hydroxyapatites have been widely used as implantable materials in medicine. Thanks to its biocompatibility with bone tissue, it is widely used as a bone substitute. When placed in the body, it has no cytotoxic properties. This means that hydroxyapatite is not toxic to body cells [1]. Thanks to its bioactive properties, it can connect directly to the bone, thus creating a biological connection. This feature and the porosity of the material allow it to penetrate through the bone tissue. It enables a very strong and durable implant connection. The Young modulus is the basic parameter determining the mechanical properties of solids state as porous foam. Hydroxyapatites are characterized by a very high brittleness, which makes it practically impossible to fix the sample in the jaws of measuring instruments. A strong secure clamp destroys the specimen and a weak clamp causes shifts and backlash, which falsify the result of measurement. The aim of the study was to determine the mechanical properties of hydroxyapatite foams produced by agarose gelation [2-4]. We present an optical method of static measurement of the Young modulus. The optical method based on light diffraction is noncontact and does not require calibration. The applied method does not require grips, which allows for correct determination of the static Young modulus. The Young modulus is also studied by using an impulse excitation technique [5-9]. This method cannot be used for studies of the Young modulus of dried sample of hydroxyapatite, which are soft.

\section{Sample preparation}

Hydroxyapatite can be synthesized via several methods. In this paper we study mechanical properties of porous ceramics produced by agarose gelation. After mixing the appropriate ingredients, a suspension was obtained, which was poured into moulds and placed in

*corresponding author; e-mail: ftkwiece@prz.edu.pl a refrigerator for complete cooling. The samples were dried in moulds at room temperature, then were removed from the moulds, and were dried for 3 weeks at this temperature.

Beams with dimensions of $5.5 \times 13.5 \times 60 \mathrm{~mm}^{3}$ were cut out of the previously obtained samples (Fig. 1). Due to difficulties in processing the material due to its brittleness, there have been some deviations in the dimensions shown in Table I. However, the parallelism of the walls determining the thickness of the beams has been preserved.

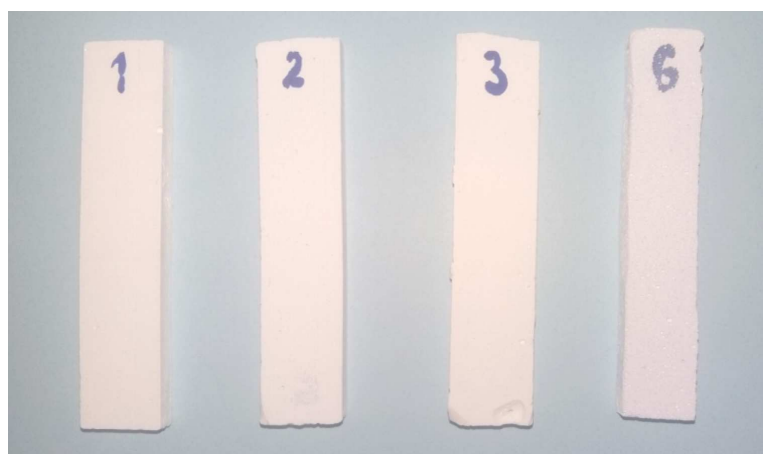

Fig. 1. Dried samples of hydroxyapatite.

The parameters of the dried samples

TABLE I

\begin{tabular}{c|c|c|c|c|c|c|c}
\hline \hline No. & $\begin{array}{c}\text { Mass } \\
{[\mathrm{g}]}\end{array}$ & $\begin{array}{c}\text { Thickness } \\
h[\mathrm{~cm}]\end{array}$ & $\begin{array}{c}\text { Width } \\
b[\mathrm{~cm}]\end{array}$ & $\begin{array}{c}\text { Length } \\
{[\mathrm{cm}]}\end{array}$ & $\begin{array}{c}\text { Volume } \\
{\left[\mathrm{cm}^{3}\right]}\end{array}$ & $\begin{array}{c}\text { Apparent } \\
\text { density } \\
{\left[\mathrm{g} / \mathrm{cm}^{3}\right]}\end{array}$ & $\begin{array}{c}\text { Porosity } \\
{[\%]}\end{array}$ \\
\hline 1 & 4.045 & 0.553 & 1.341 & 6.133 & 4.548 & 0.89 & 71.9 \\
2 & 4.055 & 0.543 & 1.350 & 6.041 & 4.428 & 0.92 & 71.0 \\
3 & 4.009 & 0.544 & 1.342 & 6.033 & 4.404 & 0.91 & 71.2 \\
6 & 1.851 & 0.549 & 1.174 & 5.962 & 3.843 & 0.48 & 84.8
\end{tabular}

The parameters of the sintered samples

TABLE II

\begin{tabular}{c|c|c|c|c|c|c}
\hline \hline No. & $\begin{array}{c}\text { Mass } \\
{[\mathrm{g}]}\end{array}$ & $\begin{array}{c}\text { Thickness } \\
h[\mathrm{~cm}]\end{array}$ & $\begin{array}{c}\text { Width } \\
b[\mathrm{~cm}]\end{array}$ & $\begin{array}{c}\text { Length } \\
{[\mathrm{cm}]}\end{array}$ & $\begin{array}{c}\text { Volume } \\
{\left[\mathrm{cm}^{3}\right]}\end{array}$ & $\begin{array}{c}\text { Density } \\
{\left[\mathrm{g} / \mathrm{cm}^{3}\right]}\end{array}$ \\
\hline 1 & 3.855 & 0.424 & 1.042 & 4.806 & 2.124 & 1.815
\end{tabular}


The samples numbered 1, 2, 3 have apparent density $\left(0.89-0.92 \mathrm{~g} / \mathrm{cm}^{3}\right)$ and porosity (71.0-71.9\%). Other porosity $(84.8 \%)$ and apparent density is in sample number 6 . The porous shaped piece (sample 1) was heated at $2{ }^{\circ} \mathrm{C} / \mathrm{min}$ to $1250{ }^{\circ} \mathrm{C}$. Later the sample was cooled by $4{ }^{\circ} \mathrm{C} / \mathrm{min}$ to $900^{\circ} \mathrm{C}$. The cooling process continued with the cooling of the furnace. The parameters of the sintered sample are shown in Table II.

Porous ceramics are mostly characterized by their porosity and apparent density. Figures 2 and 3 show the area of porous material at a magnification of 7000 times. Microstructure of ceramic foams was examined by scanning electron microscopy (SEM Hitachi S3400-N).

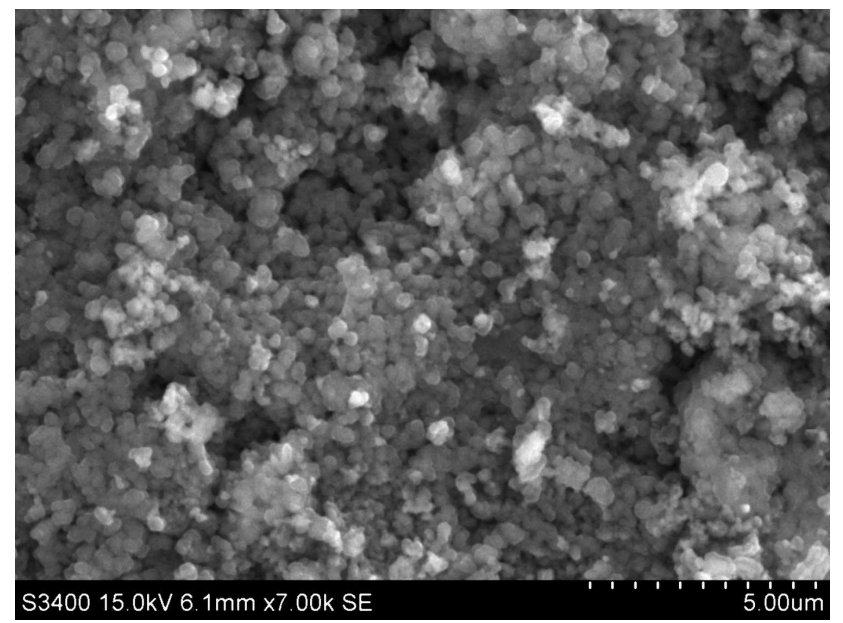

Fig. 2. SEM image of dried sample of hydroxyapatite.

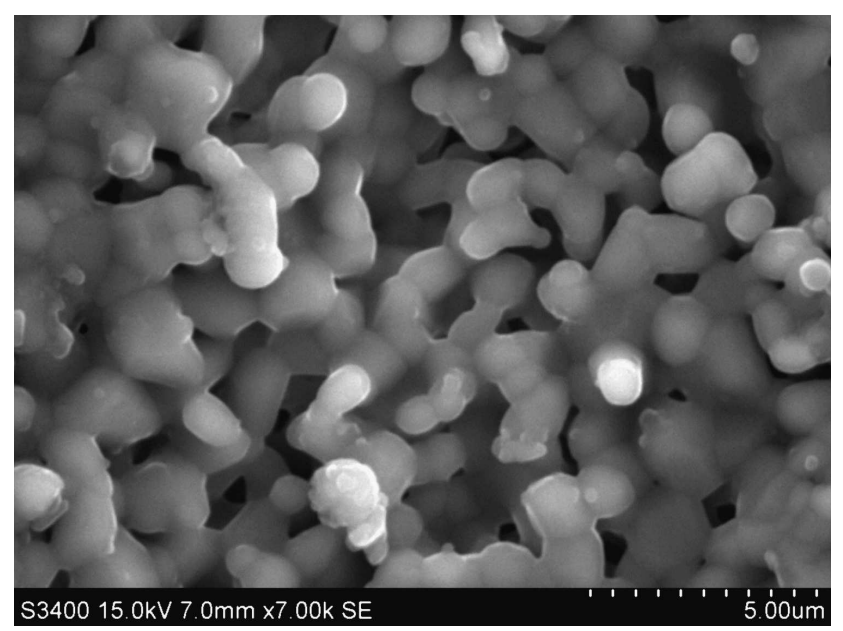

Fig. 3. SEM image of sintered sample of hydroxyapatite.

\section{Experimental setup}

The setup for the measurement of the static Young modulus is presented in Fig. 4. The diffraction slit consists of one fixed edge and one movable mirror. The

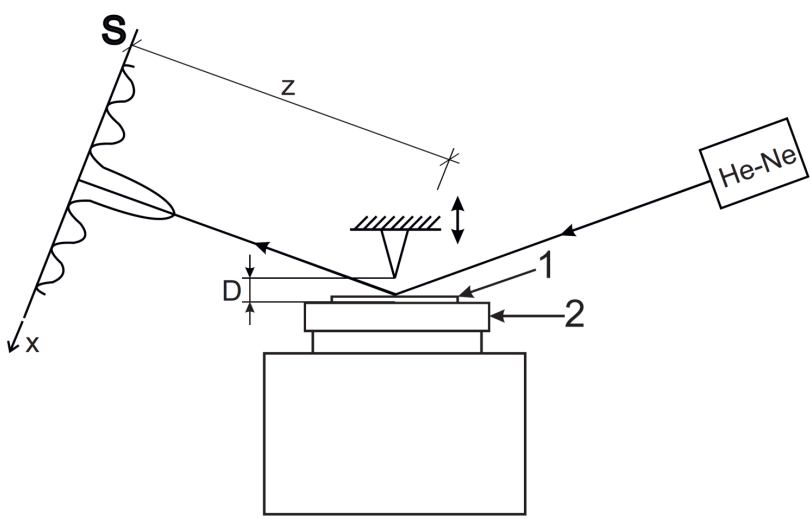

Fig. 4. Experimental setup: 1 - mirror, $2-$ hydroxyapatite (dried sample), $\mathrm{S}$ - screen, $\mathrm{x}$ - position of fringe, $\mathrm{z}$ - distance between the screen and the slit, $\mathrm{D}$ - width of the slit, $\mathrm{He}-\mathrm{Ne}$ - laser.

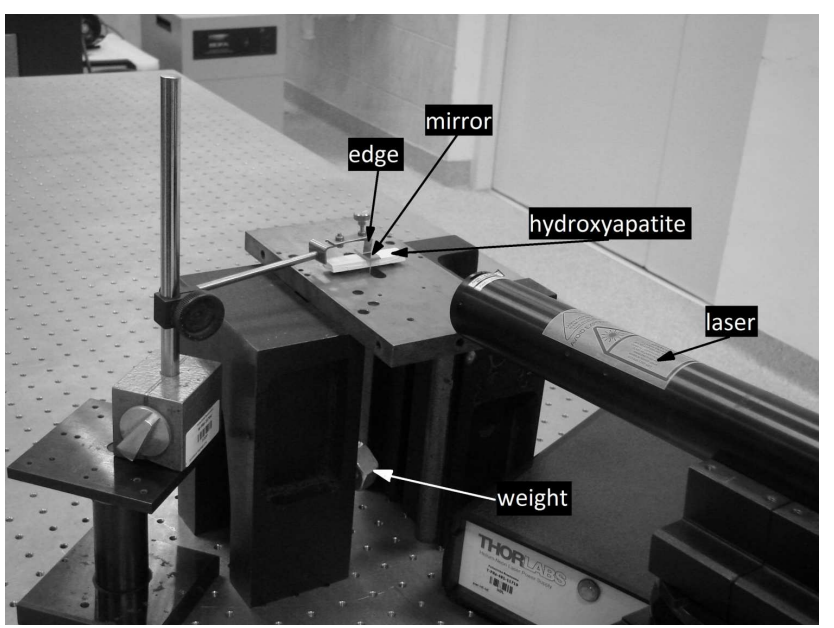

Fig. 5. Photograph of the laser diffraction system.

laser beam passes through the slit generating a diffraction pattern on the screen. Changes in the slit width cause changes in the diffraction pattern which are recorded. The width of the slit is determined by means of a non-contact, non-inertial, long distance diffractive measurement.

From the observation of diffraction distribution, the width $D$ of the slit was determined and then the deflection $f$ of the beam (Fig. 5). The intensity distribution of the diffraction pattern is described by the Fraunhofer formula [10] (Fig. 6):

$$
I(x, D)=I_{0} \frac{\sin ^{2}\left(\frac{2 \pi}{\lambda} \frac{x}{z} D\right)}{\left(\frac{2 \pi}{\lambda} \frac{x}{z} D\right)^{2}}
$$

where $I(x, D)$ is light intensity, $I_{0}$ is light intensity for $x=0, \lambda$ is the wavelength of light, $z$ is distance between the screen and the slit, $x$ is position of fringe, $D$ is width of the slit.

On the basis of the results obtained, a graph was drawn up (Fig. 7) and a static Young module was calculated. 


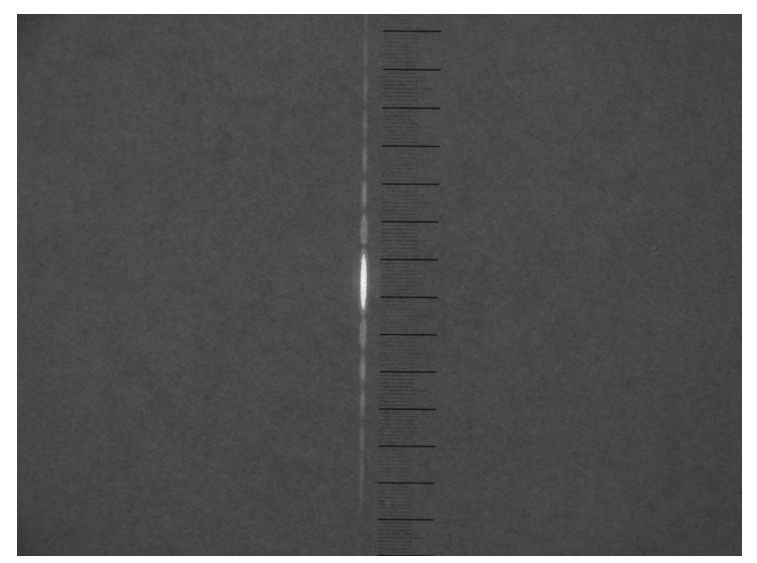

Fig. 6. The diffraction pattern produced by a slit.

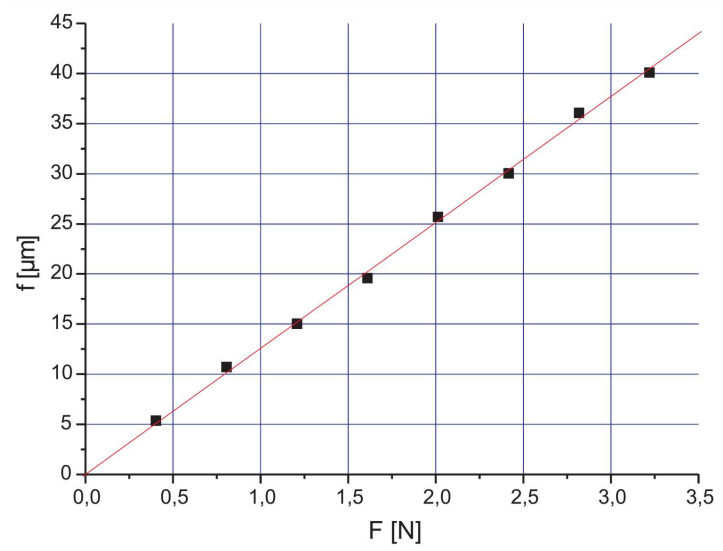

Fig. 7. Estimation of the static Young modulus of hydroxyapatite sample.

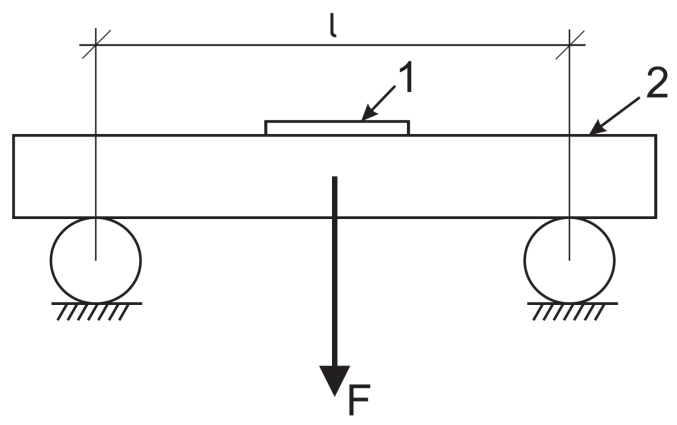

Fig. 8. The sample of hydroxyapatite: 1 - distance between supports, $\mathrm{F}$ - force, 1 - mirror, 2 - beam.

The value of deflection $f$ of the beam (Fig. 8) is obtained from the following formula [11]:

$$
f=\frac{l^{3}}{48 J E} F, \quad J=\frac{b h^{3}}{12},
$$

where $J$ is the second moment of area about the neutral axis, $E$ is Young's modulus, $F$ is force, $l$ is distance between supports, $b$ is width of the sample, $h$ is thickness of the sample.

The Young modulus value for the tried sample is $E=718.9 \mathrm{MPa}$ with standard error 7.6 MPa.

\section{The impulse excitation technique}

The impulse excitation technique is based on the analysis of the vibration of a test sample or component after it was "impulse excited" (= gently tapped). The resonant frequency and damping analyser (RFDA) is a non destructive testing device to determine the resonant frequencies of materials. It is well known that the elastic properties of a test specimen are related to its mechanical resonance frequency. The RFDA analyses the vibration induced by a mechanical impulse. A vibration is induced by a small mechanical impulse. The energy is dissipated by the material into a vibration. This vibration has a frequency spectrum according to its resonant frequencies which depend on:

- the elastic properties of the material,

- the geometry,

- the density.

Each frequency will damp according to the energy absorption of the material. The exact micro structural origin of damping, or internal friction or mechanical loss varies from one class of materials to the other. The vibration is detected by a transducer. The transducer produces an electrical signal which is sent to the computer where the signal will be analysed. The specially developed mathematical algorithm calculates each frequency and damping from the detected frequency spectrum assigning to each frequency a sinusoidal, damped vibration (Fig. 9). The dynamic Young modulus value for the tried sample is $E=1.19 \mathrm{GPa}$ and for the sintered sample $E=30.24 \mathrm{GPa}$ with standard error $0.34 \mathrm{GPa}$. The standard [5] provides the Young modulus with the use of the impulse excitation technique.

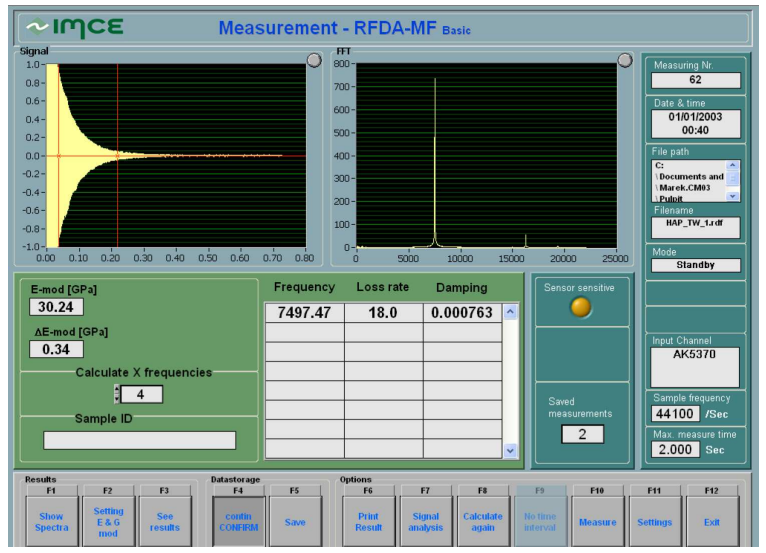

Fig. 9. The monitor shows the frequency spectrum of the sintered sample.

\section{Conclusion}

The laser system can be used to determine the static Young modulus of dried samples. We obtained value of the Young modulus $E=0.719 \mathrm{GPa}$ with standard error $0.008 \mathrm{GPa}$ for the dried sample. The laser system 
uses diffractometers and the measurement is remote, noncontact, and inertia-free. The impulse excitation technique is designed to determine the dynamic Young modulus of hard materials and there are difficulties for soft materials. The dynamic Young modulus value for the tried sample is $E=1.19 \mathrm{GPa}$ and for the sintered sample $E=30.24 \mathrm{GPa}$ with standard error $0.34 \mathrm{GPa}$. The dried sample is a soft material and the Young modulus is of low value. The sintered sample is a hard material and the Young modulus is much higher. The soft material gives different resonance frequencies while a hard material gives a recurring resonance frequency using an impulse excitation technique. Measurement of the Young modulus by diffraction method is better than the impulse excitation technique for soft materials.

\section{Acknowledgments}

This project was financially supported by Rzeszów University of Technology (No. DS.FC.18.001/2018). The authors wish to thank Professor Marek Potoczek for the hydroxyapatite.

\section{References}

[1] A. Slosarczyk, M. Potoczek, Z. Paszkiewicz, A. Zima, M. Lewandowska-Szumieł, A. Chróścicka, Ceram. Mater. 62, 224 (2010).

[2] M. Potoczek, A. Zima, Z. Paszkiewicz, A. Ślósarczyk, Ceram. Int. 35, 2249 (2009).
[3] M. Potoczek, Mater. Lett. 62, 1055 (2008).

[4] P. Sepulveda, F.S. Ortega, M.D.M. Innocentini, V.C. Pandolfelli, J. Am. Ceram. Soc. 83, 3021 (2000).

[5] M. Dal Bó, V. Cantavella, E. Sánchez, Dachamir Hotza, F.A. Gilabert, J. Non-Cryst. Solids 363, 70 (2013).

[6] Ling Feng He, Yi Wang Bao, Jing Yang Wang, Mei Shuan Li, Yan Chun Zhou, J. Am. Ceram. Soc. 92, 445 (2009).

[7] A.S. Maxwell, S. Owen-Jones, N.M. Jennett, Rev. Sci. Instrum. 75, 970 (2004).

[8] I. Štubňa, A. Trnik, L. Vozár, Acta Acust. united with Acustica 97, 1 (2011).

[9] Standard Test Method for Dynamic Young's Modulus, Shear Modulus, and Poisson's Ratio by Impulse Excitation of Vibration, American Society for Testing and Materials E1876-99, 1999.

[10] T.R. Pryor, O.L. Hageniers, W.P.T. North, Appl. Opt. 11, 308 (1972).

[11] A.H. Cottrell, The Mechanical Properties of Matter, Wiley, New York 1964. 